\title{
English for Engineering Students: A study of the teaching- learning system in the Indian context
}

\author{
Ms. Malavika Mohapatra, Dr. Swayamprabha Satpathy \\ Assistant professor, Dept of Humanities \& Social Sciences \\ Assistant professor, Dept of Humanities \& Social Sciences
}

\begin{abstract}
Proficiency in English is very important for students of Engineering and other professional courses because it is the medium of instruction in higher academics besides being the lingua Franca of all global transactions. It is a welcome development that people in the field of technical and professional education have now recognized the emerging scenario and are supporting the view that English is the dominant language of science and technology and an indispensable part in an engineer's professional training.

However through a study of secondary data and published literature on the subject of English language proficiency of engineering students in the Indian context and first hand observation by the authors themselves it is observed that inspite of intervention programs, an overwhelming number of our graduating engineers lack appropriate proficiency in English, which frustrates their attempt to acquire the required communication skills in order to be employable.
\end{abstract}

This paper therefore explores the significant factors and their impact on the communicative proficiency of engineering students in India.

Key words: Proficiency, Communication Skills, Fluency, Employability Skills,

\section{Introduction}

Proficiency in English is very important for students of Engineering and other professional courses because it is the medium of instruction in all higher academics and it is widely used as the medium of communication in all offices within our country. English is also the predominant language for international commerce, trade, international relations, tourism, science, technological research, and education. Engineering students have to use English to deal comprehensively with the countless lectures conducted in English, comprehend countless sentences and paragraphs written in English in the engineering text books and reference books, tutorials, projects and dissertation papers. Academic success therefore is predominantly dependant on English language proficiency of the students. Besides that the world is increasingly becoming a small place and job opportunities are not just limited to India alone, thus competence in English is very important for the engineering students in India, not only for their academic career but also for their prospective professional life. With this background it is pertinent to explore the teaching-learning process effectiveness and the perspectives on the proficiency in English for our engineers.

\section{The National Perspective}

From Indian national development perspective proficiency in English for our scientists and engineers is important English as it is the dominant language of science and technology. Proficiency in English is also important for the academics and research bodies as a good number of the scientific papers or journals in the world are written in English.. English as an international language of science (EILS) has led some users to enjoy preferred treatment and status. Hence it is imperative that our students have the requisite proficiency in English if we want our country to occupy leadership position in the field of science and technology.

This country has lost the advantage it had to become the most preferred destination for the IT and ITES industry and for providing teachers of English to countries like China, Turkey, South Korea and others. In this era of globalization and job crunch, if our engineers and scientists continue to be complacent about their proficiency in English Language, the country shall once again be relegated.

\section{The Individual Perspective}

Decades ago it was generally believed that engineers were to do technical things behind stage and therefore did not need any higher level of proficiency in English. The engineering curriculum therefore didn't give any emphasis to developing communication skills in English. With India fast becoming a global economy and English being the language of global business, the Indian companies are increasingly focusing on English language skills of employment seeking candidates. Moreover, English is the medium of interpersonal communication in the corporate and therefore having good command on English language has become even 
more crucial. Engineers usually work in groups and this very nature of their work demands mutual cooperation and effective interpersonal communication within and outside the organization in order to understand and coordinate with co-workers and accomplish their projects. To be able to do so engineers need to possess high level of listening comprehension, speaking and reading fluency and good writing skills in English. It would be squarely wrong to depend solely on technical knowledge and skills, which could be less than adequate due lack of language comprehension and production skills in English, to progress in one's professional career. Good communication skills in English and sound domain knowledge is also crucial to make the most out of the globalised job market

\section{Literature survey on English Proficiency of Indian Engineer-aspirants}

The authors undertook a literature survey on the subject of linguistic proficiency and communicative competence and looked for secondary data about the English proficiency status of engineer-aspirant Indian youth. Thereafter we undertook a field survey to obtain first-hand experience of the ground reality.

The need for engineering students to acquire communication skills along with technical skills, to facilitate career success and community engagement has been increasingly communicated by educators and industry professionals alike. Various essential communication skills mentioned include conflict resolution, teamwork, and awareness of social justice, ethics and sustainability. However, as highlighted by Adams and Missingham (2006) the need for improved communicative competence in engineering graduates has been the most widely discussed in research and the engineering profession. Engineers increasingly, work in knowledgeintensive fields that require both problem-solving skills and high level communication (Alvesson 2004). Riemer (2002) claims the graduate engineer must be able to present this knowledge with an excellent standard of communication skills along with engineering knowledge and technical expertise.

According to Najar (2002) "communicative competence, including teamwork and professional writing skills for example, the ability to research, write and format basic research reports as well as develop formal oral presentation skills is important to prepare students for both academic success and the workplace." Kang Shumin says: "Learning to speak a foreign language requires more than knowing its grammatical and semantic rules". He further opines that: "Learners must also acquire knowledge of how native speakers use the language in the context of structured interpersonal exchange, in which many factors interact".

The engineering degree can be divided into two primary constituents; the technical component, comprises the knowledge of physical and mathematical principles, analytic techniques and modeling along with a set of generic skills which include ability for team working, effective communication, problem solving and critical thinking ability and a variety of other issues associated with the profession of engineering. Thus all engineering programs must ensure that their graduates develop to a substantial degree the following generic attributes or capabilities. The generic attribute of the engineering degree should aim at developing the ability to communicate effectively, not only with engineers but also with the community at large.

Communication is a multidisciplinary activity that encompasses broad areas such as listening, speaking, reading, and writing. Effective communication skill is an essential for the engineer. It is not only the academics but engineers require effective communication as an essential employability skill in the competitive global work arena. Unfortunately reviews show that this very skill is severely lacking, subsequently affecting the general employability of engineering students.

Business standard quoted a report of a recruiting and HR training firm, Aspiring Minds, which says that " 43 percent of engineers cannot write correct English and lack accuracy in English grammar. It is further understood from the report that 25-35 per cent of engineers are unable to comprehend effectively written and spoken discourses in English, which include day-to-day conversations, academic lectures and texts." The firm, on the basis of a test conducted covering a very large group of candidates, has asserted that a mere 3.25 per cent of engineering graduates are software-industry-ready, and ready to be hired without needing further training. Almost 73 per cent of those who took the test conducted by the firm were found to lack capability to communicate in English, while 95 per cent were found to be short on technical skills. The report goes on to observe, "This is, and in the future shall become, a major impediment to the growth of entrepreneurship and IT companies in India." It adds that this could even affect the growth of the economy of our country.

Several other surveys made by different organization have similar alarming findings to report. For example, IRIX (Industry Readiness Index) Survey conducted in 2012 by Purple Leap, an organization that trains students to be job-ready, revealed that one third of the graduates from the Tier 2, 3 and 4 engineering colleges are not employable even after interventional training. It reports that students across the country fall short of desirable levels in generic abilities, including communication skills and problem-solving capabilities in particular. TeamLease, another private staffing company which claims to be a heavy recruiter, published a report- India Labour Report for the year 2012, in which it has stated that un-employability is a bigger issue than unemployment. Mohit Gupta, Senior Vice President of TeamLease says, "The higher education situation in the country is pathetic..." 
The National Employability Report Engineer Graduates 2014, is based on the graduate class of 2013, and covers 1.2 lakh engineering students from more than 520 engineering colleges across 18 Indian states. The report delves into the employability of engineering graduates -- their capability, qualifications and aspirations

Himanshu Aggarwal, CEO, Aspiring Minds, said "Looking at state-wise distribution of employable talent, we can see that while certain states produce huge quantity of engineers, the average employability is significantly low," ...It is clear that states need to be conscious towards better education quality rather than building more capacity."

According to Janette Marx Senior Vice President at Adecco Staffing U.S, “'“It's interesting to see how the definition of the skills gap has evolved from being so heavily focused on technical and computer skills to 'soft' skills related to communication and creativity.....Educational institutions may overlook these elements in today's digital age, but schools must integrate both hard and soft skill sets into their curriculums, which in turn will help better prepare candidates and strengthen our country's workforce."

Abraham, Rao and Punnoose lament that a large majority of the engineering students lack analytical thinking skills, debating and public speaking skills it affects their problem solving abilities and proficiency in using the language. With globalization and the ever-increasing international exchanges, there has been a remarkable gap between the professional competencies and the corresponding communication competencies. One of the major problems of professionals in India is communicating effectively in English which is most evident in the field of science \& technology. This is due to several factors to in the environment, the learning and teaching approaches, attitude and motivation towards the English language etc.

\section{Analysis and Discussion}

\section{Limitations and Scope}

Due to constraints of time and resources this study is confined to engineering students and colleges in Odisha. However the state of Odisha (India) receives a cross section of students coming from almost all over India to study at the major engineering colleges of Odisha. Moreover secondary data prove that the teaching learning system and outcome is almost the same all over the country. The authors being English teachers of engineering college themselves have also based this study on observation, discussion and analysis in their immediate environment.

Basing on the foregoing discussions we hypothesized that there is serious gap in the English language teaching-learning process in the Indian schools and colleges and therefore we made an attempt to explore it.

As the very first step we analyzed the English language syllabi of ICSE, CBSE and State Boards and it was observed that the ICSE English syllabus aims at developing and integrating the use of the four language skills i.e. listening, speaking, reading and writing for the purpose of effective communication. Students are expected to develop a functional understanding of the grammar, structure, and idiom of the language; develop the capacity to read efficiently and access information effectively; develop an appreciation of good literature and experience through literature the thoughts and feelings of people of the world. To summarize, students are expected to develop their ability to exchange thoughts, ideas, and opinions through both oral and written discourses in the target language i.e. English. The English course designed by the Central Board of Secondary Education and the Boards of secondary education in the states (which follow the CBSE pattern by and large) also aim at developing students' communicative competence in English as is evidenced from the learning outcomes enumerated in these syllabi.

Despite very good syllabus developed by the various Boards of Secondary education, English language proficiency in the Indian schools and colleges have remained inhibited and the factors for such dismal situation can be attributed to failure of English language teaching-learning-evaluation process which ultimately affects their appreciation of higher levels of academic learning. We have observed that in vernacular medium rural and urban schools English is almost treated as an alien language and proficiency in the language exists at a literal rather than at inferential level and where meaningful interaction in English is rare. Many teachers in vernacular medium schools themselves have low levels of proficiency in English and they too operate at the literal level. Although they are required to teach in English, they often resort to code switching while teaching and hand out summaries and notes in English which the students rote-learn to pass examinations.

Students often resort to decoding English into their mother tongue or the first language whichever they find convenient and then reinterpret their thoughts into English, a situation potential for occurrence of considerable misinterpretation. This results in the inability to clearly express their thoughts in both written and spoken forms; all of which translates into high communication failure potential. Once students from such an environment enter higher education, they are certainly disadvantaged and often are unable to adapt to the discourse-based environment in the universities and institutes of higher education. The situation for students coming from English medium schools is only slightly better than the vernacular medium counterparts.

It is observed that the evaluation system of the various examining bodies like ICSE, CBSE and State Boards lack tooth in evaluating true proficiency levels of their students. These examinations can at best be 
described as ritualistic. At the end of the school curriculum students sit for examinations and are awarded scores. But these scores in reality do not appear to be reflecting the true proficiency of the students. In English medium schools where students enter without adequate exposure and fluency in the target language, students genuinely feel overwhelmed as everything is transacted in English. In order to overcome the problems of inadequate English comprehension, students in order to survive, resort to rote learning strategies. Students from English medium schools also lack the ability to comprehend English spoken by native speakers. At the $10+2$ level students both at schools and college level study English (particularly literature) like any other subject and the ultimate motive is to pass in the subject, therefore the syllabus and teaching methodologies do very little to enhance the communicative proficiency of students.

It is also to be noted that students do not speak the English language or listen to it on a constant daily basis. Speaking the language is not mandatory in many English medium schools and not at all necessary in vernacular mediums. This highly affects the basic English learning skills of all students.

\section{Communicative Language Teaching in Engineering Colleges}

Secondly the English course and teaching methodology in engineering colleges of Orissa was analyzed. While everyone agrees that adequate communication competencies are crucial for good engineers, teaching of English in engineering colleges in India has always held an uncertain status. Much attention has not been given to these curricula. Language learning is a skill-oriented activity and needs an entirely different pedagogic approach from the one used for other conventional Courses. As the learners are adults they have different learning styles which must be respected

Students follow a common syllabus comprising of the Communicative English course and Business Communication at the undergraduate level. The colleges have the liberty to introduce it either in the first year (in either 1st or 2nd semester) or in the second year (either in 3rd or 4th semester) of the engineering programme. In most cases, it is either a two or a three-semester course, comprising of both theory and practical classes.

In all engineering colleges in Odisha English is taught under the subject Communicative English which is part of the regular course and taught basically in the first and/or the second year of the engineering degree. The Communicative English course is divided into Theory and Lab (Practical) sessions.

The overall objective of the course is:

1. To develop and integrate the use of four language skills; listening, speaking, reading and writing abilities of the students.

2. To enable the learner to communicate effectively and appropriately in real life situations.

3. To use English effectively for academic purposes across the curriculum.

The lab training in colleges is generally given with the assistance of Networked Computers and specially designed software. The objectives of the practical training are given below.

1. To equip students of engineering and technology with effective speaking and listening skills in English along with soft skills and people skills, this will make the transition from college to workplace smooth

2. To enhance students' proficiency at Placement interviews, Group Discussions and other recruitment exercises.

The teacher in an engineering college has little motivation because much of the teaching is remedial in nature and offers little scope for professional growth. On the other hand the student at that stage (first year), the student is in no frame of mind to work on English. They want to be exposed to higher learning experience rather than to seemingly irrelevant English writing and grammar. It is only in the third year onwards that the students become aware of their needs and are then desperately looking for help which, due to syllabus structure and time constraint, becomes difficult and almost impossible.

There is, therefore an urgent need to find a workable solution so that the students in professional colleges have an opportunity to acquire skills on which their professional excellence depends.

\section{Conclusion}

The above discussion points to a problem in teaching English as a second language and basically to the teaching-learning process. In order to find a solution a few questions need to be answered; what is the importance of English for engineering students? To what extent can the -academic and communicative goal be achieved? Both the questions have been answered already in the foregoing paragraphs. Students learn at different rates depending on their age, attitude, motivation, personality, learning approach and previous education and learning experiences.

Most students in India entering English medium school have limited exposure to English language and have not generally developed adequate conversational and interpersonal skills in English by that time. Therefore they would need more time to develop the required skills for successful learning in the regular classroom situation. Learners who have had substantial exposure to English language before entering a school require less 
support and time before they are fully integrated into the regular classroom. The primary school English syllabus rather overwhelms the students and forces them to rote learning and hence the desired outcome is not accomplished.

In the Indian context students are learning English which is a minority language. It takes about 10000 hours of immersion in the target language to attain fluency (Archibald et al, 2007; Cummins and Swain, 1986). In our English medium schools today students interact in English in classrooms only. Considering that there are 4 periods on each working day where interaction takes place in English (Hindi and other languages classes are excluded) and there are only 180 working days in a year, immersion in English language works out to 7200 hours for a student who enters the school in the standard I. On the other hand direct immersion in the language in vernacular medium schools is far too less (1080 hours) as most schools introduce English in class 5 or 6 . Indirect immersion in English language is practically non-existent.

Such levels of immersion though could be adequate for rote learning and passing the board examinations is inadequate to enable the students to attain the desired level of linguistic competence in English to meet the challenges of higher education environment and communication needs. In learning a language, the aim is to be able to utilize the language in day-to-day tasks and also to meet the academic demands. The linguistic competence is crucial for the students and teachers as well. The teaching-learning process should ensure that learning does take place and the learners do achieve their long-term goals which include learners' ability to communicate in the target language outside of classrooms and realize various professional/career opportunities. Although, the technical universities do have programmes which run for one or two semesters, situation does not register any appreciable change in the communication skills of the students in reality due mainly to immersion insufficiency.

The students' learning problem is compounded by the lack of appropriately trained English language teachers at all levels. Focus on improving English language proficiency of the teachers could help in improving the situation as students may have very little to learn from their teachers if they themselves are not truly proficient. The English proficiency of teachers in rural areas and even in various English medium schools is far from satisfactory. A mere university degree in English or a degree in education does not really guarantee proficiency of the teachers in English language teaching. Besides university degrees, graduate/post graduate, the teachers must qualify benchmarked proficiency tests in order be considered eligible as teachers of English because the need of the hour is to teach English as a foreign language. Teachers of other subjects should also be asked to take language proficiency tests because, students' learning of English is not necessarily restricted to English classes but will have to happen through various subjects which are part of the qualifying examinations.

\section{Suggestions and Recommendations}

A curriculum that maximizes the learning of all students is one that recognizes and celebrates diversity and engages all students in intellectually challenging learning experiences. It provides students with clear guidelines on what they are learning how they will be assessed, the objective and outcome. It involves a range of teaching strategies to meet different teaching needs and explicit teaching to scaffold students' learning so that they develop and consolidate the required knowledge and skills to meet the anticipated future demands of work and citizenship. To ensure that the intended learning goals for all learners are met the essential components of planning, pedagogy, assessment and reporting need to be addressed.

We recommend that all students should be provided with the opportunity and learning ambience so that they can engage with and participate in the learning English language and master competence at the appropriate grade level specified and mandated in curriculum documents. Since Curriculum is much more than a syllabus which outlines what is to be taught, we are of the opinion that schools and teachers should enable all students to access and achieve the learning described in the mandated curriculum documents. This may involve adjustments to curriculum tasks, teaching materials, classroom organization and management, learning experiences, teaching styles and assessment procedures. It requires the curriculum to be designed for flexibility and to be able to support teachers to be responsive to students' educational needs in proactive ways.

Although theoretical knowledge of engineering along with technical competency is what is sought and taught in the Faculty of Engineering, it appears that this should be coupled with communication. The importance of communication skills is also highlighted in research conducted in industry and engineering job markets, more specifically, with regard to the Employability Skills Profile (ESP). Based on the findings of the study conducted by us it is recommended that a bench mark proficiency level should be made mandatory for students wishing to join graduate engineering courses. This will induce the students to acquire higher level of proficiency in all areas of language skills.

It may be considered to select one of the band scores of IELTS or any other equivalent international English language proficiency Testing System to set it as the bench mark for entry into graduate engineering courses. Later in the college the curriculum may be designed to provide and facilitate involvement of learners more in interactive sessions in classrooms so that they are able to strengthen their communicative competence. 
Additionally, teaching technical and business communication should be at a much higher level than at what the English syllabi in the engineering colleges offer at present. Thus, course and curriculum designing and activities would help to achieve the goals and objectives of language study. It is also recommended that teachers are given enough opportunity for professional development so that they improve their own standard and gain knowledge on effective teaching strategies that can be implemented at classroom level in the engineering institutional context.

\section{References}

[1]. Adams, K \& D Missingham (2006) Contributions to Student Learning: An overview of Engineering Communication courses in Mechanical Engineering education, School of Mechanical Engineering, University of Adelaide, unpublished (internal) report.

[2]. Alvesson, M (2004) Knowledge Work and Knowledge-intensive Firms, Oxford University Press, Oxford

[3]. Riemer, Marc J (2002) English and Communication Skills for the Global Engineer', Global Journal of Engineering Education, vol. 6 , no. 1 .

[4]. Najar, Robyn L (2001)_Facilitating the development of disciplinary knowledge and communication skills: Integrating Curriculum‘, paper presented at the Annual Meeting of the Australian Association for Research in Education, Freemantle, 2-6 December

[5]. Kang Shumin, "Factors to consider: Developing Adult EFL Students' Speaking Abilities”,, Jack C. Richards, Willy A. Renandya. Ed Methodology in Language Teaching: An Anthology of. Current practice CUP, 2002 : 204.

[6]. Business Standard, Wednesday, March 6, 2013; www.businessstandard.com

[7]. http://www.thehindu.com/todays-paper/tp-features/tp-educationplus/survey-findings/article5013275.ece

[8]. http://www.forbes.com/sites/ashoka/2014/03/04/two-sides-of-the-same-coin-the- employment-crisis-and-the-education-crisis/

[9]. http://ibnlive.in.com/news/best-engineers-come-from-delhi-bihar-and-jharkhandsays- report/449297-3-233.html

[10]. Archibald, J., Roy, S., Harmel, S., Jesney, K., Dewey, E., Moisik, S., et al. (2006). A review of the literature on second language learning.

[11]. Cummins, J. and M. Swain. (1986). Bilingualism in Education. London, England: Longman. 